\title{
LA BIOÉTICA COMO SOPORTE DE LA BIOSEGURIDAD
}

\author{
Roberto R. Irribarra Mengarelli*
}

Resumen: Las normas de bioseguridad implican un costo adicional que debe manejar el cirujano dentista. En una economía de libre mercado, en la cual el precio es el principal factor de comparación para elegir al prestador, la incorporación de un nuevo ítem deja en desventaja al prestador responsable, en beneficio del que no considera estas normas. La imposibilidad de ejercer un control riguroso sobre todos los prestadores demuestra que la única posibilidad de lograr una aplicación uniforme de normas de bioseguridad es la existencia de valores individuales en los odontólogos. En este punto la bioética cobra vital importancia para apoyar la atención odontológica.

Palabras clave: bioseguridad, economía de libre mercado, bioética

\section{BIOETHICS AS A SUPPORT FOR BIOSECURITY}

Abstract: Bio security norms imply an additional cost that has to be managed by the dentist-surgeon. In a market economy, where price is the principal comparison factor for the choice of a provider, a new item leaves the responsible provider in disadvantage facing those who don't consider these standards. The impossibility to exert a strict control on effective bio-security rules demonstrates that bioethics plays a vital rôle backing odontological service.

Key words: biosecurity, market economy, bioethics

\section{A BIOÉTICA COMO APOIO Á BIOSSEGURANÇA}

Resumo: As normas de biossegurança implicam num custo adicional ao cirurgão dentista no seu exercicio profissional. Numa economia de mercado, em que o preço da prestação de serviço é o principal fator de comparação para a escolha do prestador, a incorporação de um novo item deixa em desvantagem ao prestador responsável, em benefício daquele que não leva em conta estas normas em seus procedimentos. A impossibilidade de exercer um controle rigoroso com todos os prestadores faz com que a única possibilidade de lograr uma aplicação uniforme de normas de biossegurança efetivas por parte de todos eles, seja a existencia de valores individuais nos odontólogos. Este é um ponto em que abioética ganha importancia vital para apoiar este aspecto da atenção odontológica.

Palavras chave: biossegurança, economia de mercado, bioética,

Profesor Asistente de la Clínica Integral del Adulto. Facultad de Odontología. Universidad de Chile Correspondencia: Irri@entelchile.net 


\section{Introducción}

La atención médica en general, y más la atención quirúrgica, están muy condicionadas por la posibilidad de contaminar al paciente con microorganismos externos, que pueden ser causa desde patologías tan comunes como un resfrío hasta enfermedades tan graves como la hepatitis o el SIDA. En el ejercicio de la odontología, especialidad preferentemente quirúrgica, existe una alta posibilidad de contaminar a los pacientes, al personal o a quien está prestando la atención. El medio bucal es el hábitat normal de 300 especies distintas de microorganismos que están presentes cuando el dentista realiza sus tratamientos.

El paciente y el personal que trabaja con el odontólogo desconocen las características de la flora de la boca, los mecanismos de transmisión de las enfermedades susceptibles de ser contraídas en la atención dental y las consecuencias de estas enfermedades, por lo tanto, la responsabilidad de velar por la seguridad de todo su entorno es del cirujano dentista.

Lo habitual en odontología, así como en otras especialidades de la medicina, es que el profesional asuma un rol vertical y que lo que él dictamina para su paciente o para los procedimientos que se realizan bajo su dirección debe ser acatado sin mucho cuestionamiento por parte del resto de los involucrados. En bioseguridad esto es aún más marcado. El conocimiento profundo y la experiencia en la aplicación de las normas de bioseguridad no son habituales en odontología. Se han hecho progresos importantes: el uso de barreras como la mascarilla y los guantes de procedimiento prácticamente son de aplicación universal, pero ello es porque son las medidas que el paciente puede controlar fácilmente. Sin embargo, las de mayor importancia tienen todavía mucho camino por recorrer. La reflexión bioética es de crucial importancia en la formación del odontólogo, tanto en la apropiación de valores como en crear conciencia sobre la aplicación de normas de bioseguridad. Como señala Fernando Lolas, se trata de "atenuar los dilemas" que en esta área se le presentan al clínico(1).

\section{Responsabilidad con el medio ambiente}

La actividad odontológica, al igual que todas las actividades humanas, produce desechos que pueden afectar al medio ambiente. Desde la manufactura de los equipos e instrumental dental hasta la aplicación de medidas preventivas, como la fluorización del agua potable o las aplicaciones que hacemos directamente a la población mediante colutorios, barnices o el flúor presente en los materiales de restauración, tenemos subproductos que interactúan con el medio ambiente e influyen en los procesos naturales. La ecoética debe estar presente en todos los niveles de la actividad odontológica. Son innumerables los trabajos que entregan evidencia acerca de los efectos de los biomateriales sobre el medio ambiente. A modo de ejemplo, mencionemos la posibilidad de aumentar el mercurio residual en los cursos de aguas servidas(2) y cómo ello puede influir en los alimentos provenientes del mar.

\section{Responsabilidad con los pacientes}

Sobre la base de que la odontología es una actividad quirúrgica, sea sobre tejidos duros o blandos de la cavidad bucal, existe la posibilidad de contaminar a nuestro paciente con microorganismos patógenos. Para disminuir este riesgo existen protocolos de atención para todas las acciones que se realizan en odontología. Éstos han extremado la aplicación de barreras e implican asignación de recursos a este aspecto de la prestación.

En las últimas dos décadas, a partir de lo anterior y por la generalización de la aplicación de políticas económicas de libre mercado, se produce el siguiente cuadro: 
- Los pacientes se informan del riesgo de contaminarse en las consultas dentales y exigen clínicas limpias y uso de guantes durante la atención. Preguntan por la esterilización del instrumental.

- Los dentistas toman conciencia y temen contagiarse mientras atienden a sus pacientes. Implementan normas de bioseguridad.

- La economía mundial se vuelca hacia políticas de libre mercado y la salud entra en procesos de libre competencia.

- Los costos de la aplicación de normas de bioseguridad son asumidos con cargo a las utilidades de los dentistas o servicios dentales, y los aranceles de referencia de las prestaciones dentales no son recalculados.

- Ante la baja evidencia de contagio durante la atención dental, aparecen cuestionamientos a la aplicación universal de las normas de bioseguridad por el costo que ellas implican.

- Dada esta situación, la seguridad de los pacientes sólo depende de la convicción del dentista tratante de aplicar las normas de manera universal.

\section{Responsabilidad con el personal}

Los cirujano dentistas habitualmente deben delegar una serie de tareas que se realizan en el consultorio dental. Esto por la imposibilidad de realizar todas las acciones personalmente y por la mayor eficiencia que se logra en la entrega de los servicios.

El personal que realiza labores de aseo de los consultorios, preparación del instrumental quirúrgico y del recinto de atención, y de asistencia al profesional tratante, a menudo no comprende la importancia de las normas de bioseguridad. El odontólogo adquiere entonces el carácter de depositario de las capacidades necesarias para organizar la atención, educando a su personal y controlando que no incurra en conductas de riesgo.

Las facultades de odontología de todo el mundo incluyen en sus contenidos curriculares la capacitación en microbiología y patología oral. No ocurre lo mismo en los planes de estudio de los asistentes y laboratoristas dentales o, por lo menos, no con el rigor académico que se hace en odontología. Esta realidad deja con la responsabilidad del equipo de salud bucal al dentista, único con la capacidad necesaria para evaluar los riesgos en que pueda incurrir su personal.

\section{Responsabilidad con la sociedad}

Si los cirujano dentistas toman conciencia de la responsabilidad que asumen al ejercer la odontología y están convencidos de que: a) durante el ejercicio de su profesión no pueden hacer daño a sus pacientes ni al medio ambiente; b) todas sus acciones deben ser realizadas de la misma manera a todos sus pacientes; c) las prestaciones que ellos realizan para curar las patologías que presentan sus enfermos son la mejor indicación y significarán una mejor calidad de vida; d) durante la entrega de sus servicios usan todos los elementos disponibles para proteger al personal, a sí mismos y al medio ambiente, y e) la sociedad les ha entregado la responsabilidad de los cuidados de la salud bucal, tanto preventivos como restaurativos, entonces se estarán aplicando los principios básicos de la bioética y, como consecuencia de ello, la bioseguridad -necesaria en su práctica- estará sólidamente apoyada en esos principios. Sus pacientes serán beneficiados por sus acciones y serán atendidos en igualdad de condiciones.

\section{Responsabilidad en la formación}

Es una realidad que el mercado esta regulando la atención odontológica prácticamente 
en todo el mundo; sin embargo, también lo está haciendo en la oferta de formación de cirujano dentistas, con el riesgo de que las faltas a la ética que se producen en el ámbito financiero se produzcan también en la actividad de las escuelas dentales. Esto ha provocado que autores como Whitehead y Novak propongan la aplicación de modelos de auditoría ética a las escuelas dentales(3).

Es importante destacar que entre los responsables de formar a los nuevos dentistas existe la inquietud por cuestionar y analizar la forma en que se entregan los principios éticos y cómo los alumnos los aplican en su $\operatorname{vida}(4)$.

La organización de la atención clínica por parte de los alumnos de una escuela dental de pregrado es una tarea de gran complejidad. Ellos son prestadores de servicios en salud bucal a pacientes que les son entregados para realizar sus programas clínicos. La dirección de la escuela debe entregar todos los elementos necesarios para que la práctica de los alumnos sea segura para todos los actores involucrados; éste un factor que, necesariamente, puede producir distorsiones en los niveles de bioseguridad aplicados, principalmente por el costo que estas medidas implican.

\section{Relatividad de las normas}

Sabemos que las unidades en las que trabajan los alumnos de las escuelas dentales de pregrado usan mangueras de agua que se contaminan(5). A este respecto, la Universidad de Talca realizó una evaluación del agua que pasa por esos conductos y los resultados arrojaron una amplia distribución de la concentración microbiana que va más allá de la norma(6). Esta autoevaluación no es frecuente, como tampoco la aplicación de normas que impidan esta contaminación en los equipos dentales, no sólo de las escuelas, sino en los equipos de las clíni- cas dentales instaladas en la Región Metropolitana en Chile.

En el mercado existen sistemas que permiten la desinfección de las vías de agua de los equipos dentales, pero no es una obligación instalarlos en todas las clínicas que están operando en el país.

También es una realidad que los servicios de salud con más recursos pueden fiscalizar más, que los controles de niveles socioeconómicos más altos están más expuestos a la crítica y que la inspección extrema de servicios pobres puede impedir que se entreguen los pocos servicios posibles. Las normas se aplican midiendo su efecto en la estadística de atención: no impedir la atención dental en un consultorio o en un servicio privado sólo porque en ellos no existe un sistema de descontaminación de las vías de agua.

La actualización de conocimientos que permiten mantener una atención segura no es obligatoria ${ }^{1}$. La recertificación de capacidades profesionales en odontología es voluntaria y sólo afecta a los especialistas. Los cirujano dentistas de ejercicio liberal en odontología general, que corresponden a más del $80 \%$ de los cirujano dentistas en Chile ${ }^{2}$, no tienen obligación de actualizar sus conocimientos en bioseguridad.

Si hemos convenido ${ }^{3}$ en que los valores individuales son el soporte para que los cirujano dentistas apliquen diariamente y en todo momento las normas de bioseguridad, ellos deben ser entregados o reforzados en la formación de pregrado de las escuelas dentales, estableciendo una malla o modelo moral que les permita

1 Reglamento de certificación y recertificación de especialidades odontológicas (CONACEO).

2 Estadísticas de especialistas en odontología que ejercen en Chile. CONACEO.

3 Primer Simposio de Bioética y Odontoestomatología. Universidad de Chile, Universidad de Talca, OPS Chile. 11 al 13 de noviembre de 2004 . 
tomar conciencia de los riesgos, para que creen estrategias para enfrentarlos $y$, finalmente, tengan la convicción de que su aplicación es una obligación.

\section{Malla moral de soporte para la bioseguridad}

Todos los miembros del equipo de salud bucal deben tener las competencias necesarias para enfrentar los dilemas que plantea la bioseguridad en la atención de pacientes odontológicos. Más que conocimientos teóri$\cos$-que deben ser actualizados constantemente, ya que son sometidos a validación científica en todo momento-, los miembros del equipo de salud bucal y, principalmente, el cirujano dentista, deben reconocer los riesgos en su entorno y evitar que ellos provoquen un contagio a sus pacientes.

El cirujano dentista debe mantener actualizados los conocimientos relacionados con la microbiología que están directamente vinculados con su práctica profesional. La formación de pregrado debe tomar conciencia de los riesgos y entregar todos los elementos curriculares que permitan crear los mecanismos para enfrentarlos, diseñando las medidas más seguras para ser aplicadas en su práctica. Todo esto se debe sustentar en otro concepto moral: el de obligatoriedad. "Si conozco el riesgo y sé como evitarlo tengo, entonces, la obligación de hacerlo". Una forma de aplicar esta obligatoriedad es recurriendo a la ética heterónoma, y la formación en las escuelas de pregrado debe inculcar el respeto irrestricto a las normas que dicta el Estado. Otra forma es fomentando un comportamiento que esté más de acuerdo con la ética autónoma, donde la obligación se derive de la libertad para querer y obrar conforme al deber. El verdadero acto moral implica la libertad del individuo para obrar de acuerdo con su conciencia, en su autonomía(7).
Así como el contagio de un paciente obedece a la ley del todo o nada, es decir, cuando adquiere el virus del SIDA o la hepatitis no lo hace sólo para una parte del cuerpo sino para todo el individuo, las normas de bioseguridad deben ser absolutas, de aplicación universal y asimilando esto a los principios de la ética kantiana: las mismas normas deben ser consideradas positivas por todos los individuos, tener como fin la protección del ser humano y la acción moral que esa norma determine debe tener carácter universal.

\section{Conclusión}

Se ha planteado la necesidad de enfrentar los dilemas de la bioseguridad formando a los participantes del equipo de salud con valores que constituyan un modelo moral. Éste obligará a cada individuo, por decisión propia, a tomar conciencia de cada problema de bioseguridad que sus conocimientos le permitan detectar; no podrá obviar el problema, sino que se impondrá crear una forma de evitar el riesgo y, una vez creada, se verá enfrentado a la obligación de aplicarla y comunicarla a sus colegas.

Los contenidos y competencias que se asocian a la bioseguridad y a la bioética deben ser introducidos en la malla curricular de pregrado como materia de interés básico en todo el desarrollo de la carrera. Esto contribuirá a la creación de un modelo moral que soporte la práctica diaria de la bioseguridad.

La obligación emanada de normas cuya aplicación se deja a la buena voluntad de los profesionales no tendrá efecto alguno si estos profesionales no tienen un modelo moral basado en las costumbres, en el consentimiento generalizado, en la autoridad y en el bienestar humano y del medio ambiente. 
La bioética como soporte de la bioseguridad - R. Irribarra Mengarelli

\section{Referencias}

1. Lolas F. Bioética: el diálogo moral en las ciencias de la vida. 2a Edición. Santiago de Chile: Mediterráneo; 2001: 8 .

2. Conley JF. A perennial controversy. Calif Dent Assoc J 2001; 29:475-477.

3. Whitehead AW, Novak KF. A model for assessing the ethical environment in academic dentistry. J Dent Educ 2003; 67: 1113-1121.

4. Bertolami CN. Why our ethics curricula don't work. J Dent Educ 2004; 68: 414-424.

5. Barbeau J, Nadeau C. Dental unit waterline microbiology: A cautionary tale. J Can Dent Assoc 1997; 63: 775-779.

6. Arriagada A, Larrucea C, Padilla MC. Control de infección en los ductos de equipos dentales de las clínicas odontológicas de la Universidad de Talca. Revista Dental de Chile 2004; 95 (2): 3-9.

7. Escobar Valenzuela G. Ética. Introducción a su problemática y su historia. $3^{\text {ra }}$ Edición, México: McGrawHill; 1994: 123.

Recibido: 03 de enero de 2006

Aceptado: 31 de enero de 2006 